Artigo Original

\title{
O envelhecimento para militares que serviram no exército brasileiro*
}

\author{
Aging of the military who served in the Brazilian army \\ El envejecimiento para militares que sirvieron en el ejército brasileño
}

\author{
Antonio Lucio Sant'Ana Junior', Ana Cristina Passarella Brêtas²
}

\section{RESUMO}

Objetivo: Conhecer o significado do processo de envelhecimento para militares que serviram por 30 anos ou mais no Exército brasileiro. Métodos: Estudo exploratório de natureza qualitativa. Foram realizadas entrevistas com 18 militares; o mais novo tinha 48 anos e o mais velho, 72 anos de idade. Na análise, emergiram três categorias: envelhecimento e velhice; a reserva no Exército brasileiro; preparação para a reserva. Resultados: Os principais resultados mostraram que para os militares a perda da capacidade funcional, a adaptação da vida fora dos quartéis e a reinvenção do convívio contínuo com os familiares são questões fundamentais no contexto de passagem da ativa para a reserva. Conclusão: Esperamos que este estudo possibilite a ampliação de reflexões a respeito do envelhecimento no mundo militar, no sentido de implementar ações para a preparação para a vida na reserva - trabalhando não apenas com os militares, mas também com suas famílias.

Descritores: Envelhecimento; Militares; Forças Armadas; Brasil

\begin{abstract}
Objective: To know the meaning of the aging process for military personnel who served for 30 years or more in the Brazilian army. Methods: A qualitative exploratory study. Interviews were conducted with 18 soldiers, the youngest was 48 years and the oldest was 72 years of age. The analysis revealed three categories: aging and old age; retirement from the Brazilian army; preparing for the retirement. Results: The principle results showed that for those in the military the loss of functional capacity, the adaptation to life outside the barracks, and continuous reinvention of living with family members are fundamental questions in the context of transition from active to retired. Conclusion: We hope this study will enable the expansion of reflections about aging in the military, to implement actions to prepare for life in retirement - working not only with the military, but also with their families.
\end{abstract}

Keywords: Aging; Military personnel; Military activities; Brazil

\section{RESUMEN}

Objetivo: Conocer el significado del proceso de envejecimiento para militares que sirvieron por 30 años o más en el Ejército brasileño. Métodos: Se trata de un estudio exploratorio de naturaleza cualitativa. Se realizaron entrevistas a 18 militares; el más joven tenía 48 años y el más viejo, 72 años de edad. En el análisis, emergieron tres categorías: envejecimiento y vejez; la reserva en el Ejército brasileño; preparación para la reserva. Resultados: Los principales resultados mostraron que para los militares la pérdida de la capacidad funcional, la adaptación a la vida fuera de los cuarteles y la reinvención de la convivencia continua con los familiares son cuestiones fundamentales en el contexto del paso de la actividad a la reserva. Conclusión: Esperamos que este estudio posibilite la ampliación de reflexiones respecto al envejecimiento en el mundo militar, en el sentido de implementar acciones para la preparación para la vida en la reserva - trabajando no sólo con los militares, sino también con sus familias.

Descriptores: Envejecimiento; Militares; Fuerzas armadas; Brasil

* Estudo desenvolvido na Escola Paulista de Enfermagem da Universidade Federal de São Paulo - UNIFESP - São Paulo (SP), Brasil, vinculado ao Núcleo de Estudo e Pesquisa sobre Saúde, Politicas Públicas e Sociais.

2 Acadêmico de Enfermagem da Universidade Federal de São Paulo - UNIFESP - São Paulo (SP), Brasil.

${ }^{3}$ Professora Associada da Escola Paulista de Enfermagem da Universidade Federal de São Paulo - UNIFESP - São Paulo (SP), Brasil. 


\section{INTRODUÇÃO}

A intenção de realizar um trabalho com militares aposentados surgiu da observação e convivência, durante mais de dez anos, com profissionais do Exército Brasileiro que, após 30 ou mais anos de serviço prestados à Força Terrestre, se encontram - muitas vezes - afastados do convívio de seus locais de trabalho, excluídos das atividades em seus lares, estagnados, não exercendo outro ofício - remunerado ou não.

Ancoramos nossas reflexões na tese de que as sociedades capitalistas supervalorizam o trabalho e quando este deixa de ser vivenciado pelas pessoas - pela aposentadoria ou pelo desemprego - elas adoecem, se lhes faltar habilidade e condições (individuais, sociais e econômicas) para incorporar e priorizar outras atividades e valores em suas vidas, comprometendo a qualidade de seu envelhecimento ${ }^{(1-2)}$.

As Forças Armadas, constituídas pela Marinha, Exército e Aeronáutica, são instituições nacionais permanentes e regulares, organizadas com base na hierarquia e na disciplina, sob a autoridade suprema do Presidente da República, destinam-se à defesa da Pátria, à garantia dos poderes constitucionais e, por iniciativa de qualquer destes, da lei e da ordem ${ }^{(3)}$.

O Exército Brasileiro tem sua origem das batalhas dos Guararapes (1648 e 1649), travadas entre as tropas invasoras holandesas e os defensores portugueses nos Montes Guararapes, ao sul de Recife, em Pernambuco. Atualmente, o integrante das Forças Armadas tem a missão de preparar a Força Terrestre para defender a Pátria, garantir os poderes constitucionais, a lei e a ordem; participar de operações internacionais; cumprir atribuições subsidiárias e apoiar a política externa do País ${ }^{(4)}$.

Para tanto, requer profissionais altamente qualificados, treinados, motivados, coesos e bem equipados, capazes de professar "valores morais e éticos, que identificam, historicamente, o soldado brasileiro". Devem defender os interesses da Pátria com o sacrifício da própria vida, pautando sua existência - como soldado e cidadão - na honradez, honestidade e senso de justiça ${ }^{(5)}$.

Ao ingressar nas Forças Armadas - em particular, no Exército -, o militar sabe que deverá se submeter às severas normas disciplinares que condicionarão sua vida pessoal e profissional, impossibilitando-lhe de exercer outra atividade profissional, uma vez que precisa estar disponível para o serviço em tempo integral - 24 horas por dia -, sem compensações extras; ancorado no dever de bem-servir à Pátria.

Para desempenhar suas atribuições e poder permanecer na carreira, o militar, precisa ter ótimo nível de saúde física e mental, sendo submetido a rigorosos exames médicos e testes físicos periódicos durante o tempo todo em que estiver na ativa. Acrescido à obrigação de se manter hígido, outra peculiaridade desta profissão diz respeito às experiências de sucessivas transferências de cidade, fator de impacto na dinâmica de sua vida familiar. Além do que, a vida nos quartéis implica riscos contínuos, dado que nos treinamentos realizados nos tempos de paz ou nas guerras, a possibilidade iminente de um dano físico ou de morte é um fator permanente ${ }^{(5)}$.

Assim, o exercício da atividade militar, por natureza, exige o comprometimento daquele que a exerce, mesmo quando, na inatividade, uma vez que permanece vinculado à profissão e, ao constituir a "Reserva de primeira linha" das Forças Armadas, pode ser convocado para retornar ao serviço ativo se necessário, conforme previsto em Lei. Assim, a inatividade para o Exército não é sinônimo de aposentadoria - o militar encontra-se em "disponibilidade remunerada". Apenas quando vai para a Reforma - por idade ou incapacidade física - fica desobrigado a manter vínculos com as Forças Armadas ${ }^{(5)}$.

Para vários trabalhadores, a aposentadoria é o momento de descanso, após longos anos de serviço, obedecendo à rotina exaustiva de acordar cedo e enfrentar meios de transportes desconfortáveis em busca do sustento da família. Todavia, "voltar ao lar", para muitos militares, não corresponde à expectativa de descanso e convívio familiar esperada, após longa jornada de trabalho, pois a passagem da categoria de ativos para inativos muda suas rotinas disciplinadas vividas no quartel durante anos.

Não raras vezes, observamos que a aposentadoria concomitante ao envelhecimento, sobretudo a velhice - traz problemas de adaptação a uma nova forma de vida que surpreende aqueles que não se prepararam para conviver com mudanças em suas práticas e hábitos diários. Acostumados à disciplina rígida e à dedicação integral ao serviço nos quartéis, o militar não dispõe de tempo extra para desenvolver outras atividades que poderiam ajudar quando inativo - para ocupar o tempo disponível, evitando os problemas psicossociais inerentes à aposentadoria e à percepção do processo de envelhecimento.

\section{OBJETIVO}

Conhecer o significado do processo de envelhecimento para militares que serviram por 30 anos ou mais no Exército Brasileiro.

\section{MÉTODOS}

Trata-se de um estudo exploratório de natureza qualitativa, uma vez que buscou proporcionar uma visão geral, aproximativa, do processo de envelhecimento de militares inativos que serviram ao Exército por 30 anos ou mais.

A opção pela realização da pesquisa exploratória decorreu da escassez de estudos sobre esta temática, o que torna difícil a formulação de hipóteses precisas e operacionalizáveis. Utilizamos a abordagem qualitativa, para assegurar a singularidade humana, expressa por meio dos significados atribuídos pelos militares entrevistados em seu 
próprio envelhecimento em relação à vida no Exército $^{(6)}$. O projeto de pesquisa foi aprovado pelo Comitê de Ética em Pesquisa da Universidade Federal de São Paulo.

O estudo foi realizado nos Clubes - de oficiais e de sargentos - do Município de São Paulo. Para tanto, foi concedida permissão institucional, para que o pesquisador pudesse entrevistar os militares inativos que frequentam esses locais. Assim um termo de consentimento institucional foi assinado pelos dirigentes dos Clubes.

Fizeram parte do estudo 18 militares do Exército Brasileiro, sendo seis oficiais e 12 praças na reserva, após 30 ou mais anos de serviço na Força Terrestre.

A amostragem foi realizada pela técnica da saturação, por meio da qual o número de participantes foi definido, a partir do momento em que as informações coletadas apresentaram repetições expressivas em seu conteúdo e, assim, entendendo que novas falas passaram a ter acréscimo pouco significativo em vista do objetivo proposto, encerramos o convite a novos narradores.

Os militares que aquiesceram participar da pesquisa, após terem conhecido o objetivo, metodologia e formas de divulgação do trabalho, assinaram o Termo de Consentimento Livre e Esclarecido.

Os dados foram coletados, no mês de novembro de 2009, por meio da técnica da entrevista com a utilização de um instrumento com questões fechadas e semiestruturadas. As entrevistas foram realizadas pelo próprio pesquisador, em data acordada com o responsável pelos Clubes dos Militares e feitas individualmente. $\mathrm{O}$ anonimato dos entrevistados foi preservado. $\mathrm{Na}$ análise dos dados, foram tratados como informantes, e as suas respostas às nossas questões foram trabalhadas em conjunto, sem destacar peculiaridades que pudessem identificar qualquer um deles, em particular.

Para efeito de apresentação dos dados, mantivemos a distinção entre os entrevistados, colocando após a citação dos seus relatos a denominação "Águia" ao nos referirmos aos subtenentes e sargentos e "Leão", quando falarmos dos oficiais, acrescida de suas idades no momento da entrevista.

Para realização da análise dos dados obtidos, partimos da premissa de que os entrevistados compartilhavam a experiência de ser militar e estar inativo, após 30 anos ou mais de serviços prestados ao Exército Brasileiro, portanto, possuiam amplas condições para objetivarem nosso objeto de estudo. Dado essa peculiaridade e a natureza da pesquisa exploratória, optamos por não fazer distinção entre as "Águias" e os "Leões", no processo da análise das narrativas, apesar de termos consciência de que existem diferenças significativas na carreira militar, capazes de interferir na qualidade da vida de seus integrantes, questão a ser trabalhada em futuros estudos.

Para a realização da análise, ordenamos os dados obtidos por meio das entrevistas, buscando - após a leitura rigorosa e crítica - classificá-los em consonância com os referenciais bibliográficos que elegemos sobre as temáticas: Envelhecimento, Trabalho, Aposentadoria/ Reserva, Exército brasileiro. Deste movimento, emergiram três categorias, utilizadas como fios condutores para a apresentação dos resultados e discussão. São elas: envelhecimento e velhice; Reserva no Exército brasileiro; e preparação para a Reserva.

\section{RESULTADOS}

\section{Apresentação dos entrevistados}

Em relação à idade, oito indivíduos tinham 60 anos ou mais e dez menos de 60 anos. O mais novo, 48 anos e o mais velho, 72 anos de idade; portanto, trabalhamos majoritariamente com adultos e idosos jovens, desvinculando a relação entre idade cronológica e aposentadoria, na qual se parte do pressuposto de que o aposentado é idoso.

No que diz respeito à aposentadoria, nove dos entrevistados estavam na reserva há mais de dez anos; seis deles de 2 a 5 anos; dois tinham menos de dois anos de inatividade e um não respondeu. Dos 18 entrevistados, oito continuavam trabalhando, e quatro deles exerciam atividades relacionadas à vida militar.

Dezesseis eram casados, um viúvo e um não respondeu. Quanto à escolaridade, três dos entrevistados tinham ensino superior completo e quatro, incompleto; sete concluíram o Ensino Médio e dois não completaram; um concluiu o Ensino Fundamental e um entrevistado não respondeu.

Quando perguntados sobre suas motivações para ingressar no Exército, dez relacionaram suas intenções à vocação, desafios pessoais, gosto pelo serviço militar; três mencionaram que tiveram influência familiar, três entenderam que era uma oportunidade de bom trabalho, dois salientaram que adentraram no serviço militar por falta de opção, em razão de problemas financeiros.

Dezesseis dos entrevistados descreveram positividades durante o trabalho militar, expressas por situações como: apoio social, sobretudo alimentação e assistência médica; cooperação no aquartelamento para o exercício da profissão; facilidade de comunicação; melhor aceitação pessoal dentro e fora do quartel; possibilidade de fazer cursos profissionalizantes, internato em escolas públicas; chance de conhecer diferentes regiões do País e cuidado com o físico.

Por outro lado, 15 dos entrevistados relataram dificuldades durante o tempo de trabalho. Mencionaram que tiveram de interromper os estudos em decorrência de horários de expediente incompatíveis com os das escolas; salientaram ter tido pouco tempo para dedicar a seus familiares; falaram sobre as divergências de opinião com superiores hierárquicos, as promoções demoradas, 
o cumprimento rigoroso às obrigações no quartel.

\section{Envelhecimento e velhice}

Quando perguntamos se tinham a percepção de que estavam envelhecendo, nove mencionaram que sim, sete disseram que não e dois não quiseram falar sobre o assunto. Solicitamos aos que responderam afirmativamente a questão, que descrevessem em que momento ou situação começaram a ter essa consciência.

A ida para a Reserva foi um marco para alguns dos entrevistados, corroborando nossa tese inicial de que o trabalhador percebe seu processo de envelhecimento, quando se ausenta do mercado de trabalho - pelo desemprego ou pela aposentadoria.

[Percebi que estava envelhecendo] depois de 10 anos de reserva, já reformado. [Sai da ativa] como praça aos 56 anos, ai é que me deparei que estava ficando velho (Águia, 72 anos).

Na minha aposentadoria, pois, somente neste momento pude notar como havia passado o tempo... (Águia, 59 anos).

Acrescido a essa percepção, temos como marco da consciência do envelhecimento a noção das perdas corpóreas intrínsecas à vida.

Percebi, quando o corpo físico ao exercitar-me, já não mais respondia com a mesma eficácia anterior e a incompatibilidade com a situação tornou-se latente e, quando senti aproximar o término do serviço ativo - é uma situação inusitada, nada fácil, pois o vinculo com a Instituição é fortíssimo (Leão, 64 anos).

O Exército brasileiro exige do militar na ativa um ótimo nível de saúde física e mental, submetendo seus profissionais a rigorosos testes. Além dessa avaliação periódica, cobra desempenho físico e intelectual no desenvolvimento das atividades diárias independente da idade cronológica do militar. A higidez física é um constructo da personalidade do militar, portanto, as perdas físicas inerentes ao envelhecimento são citadas como um marco desse processo.

[Percebi que estava envelhecendo] lá pelos 30 anos, quando jogava futebol de salão, as pernas já não acompanhavam a velocidade da bola. (Águia, 61 anos)

Eu, felizmente, sou novo; não pertenço ainda à turma da melhor idade, mas é claro, que a gente começa a mudar a partir dos 40 anos. (Águia, 53 anos)

Outra questão levantada como marco do próprio envelhecimento foi a tomada de consciência de que os filhos cresceram.

Senti que estava envelbecendo no momento em que vi os meus filhos crescendo, mas, com meus 52 anos, sinto muito futuro pela frente. (Águia, 52 anos)

Os que afirmaram não terem percebido que estavam envelhecendo, sustentaram seus argumentos no fato de serem pessoas ativas e saudáveis. Trazem no imaginário simbólico o mito de que o envelhecimento, sobretudo, a velhice implicam uma vida sem atividade, não produtiva.

Ainda não percebi [estar envelhecendo], face estar sempre ocupando a minha mente com atividades sadias que me permitem amar e servir aos meus semelhantes. (Leão, 69 anos)

Não sinto que esteja envelhecendo, pois sou uma pessoa saudável e ativa. (Águia, 60 anos)

A velhice é um estado de espirito, tenho idade, mas ainda me sinto produtivo. (Leão, 56 anos)

\section{A Reserva no Exército brasileiro}

Após, pelo menos, 30 anos servindo no Exército brasileiro, os militares que entrevistamos foram para a "Reserva de primeira linha" e, por mais que estejam em "disponibilidade remunerada" para as Forças Armadas, têm a consciência de que adentraram no universo do mundo dos aposentados. Assim, novos papéis sociais passam a fazer parte da vida cotidiana dessas pessoas.

Como qualquer aposentadoria, [a reserva] é a conclusão de um periodo produtivo no trabalho ativo e o inicio do periodo de descanso; não há facilidades e, as dificuldades são feitas pelo indivíduo e não pelo sistema. (Leão, 72 anos)

Esta experiência pode vir carregada pelo sentimento de liberdade.

O significado [de estar na Reserva] é muito bom. É a sensação de liberdade que você adquire, estando livre para onde o nariz apontar - é muito gostoso. (Águia, 52 anos)

Entretanto, a vida militar está pautada em severas normas disciplinares que acabam impactando não só a vida do militar, mas também a de seus familiares, pelo comportamento disciplinador que extrapola os muros do quartel e adentra no espaço doméstico e/ou pela ausência constante dado às exigências militares. Assim, a Reserva é um momento de reflexão sobre a relação do militar com a sua família.

$A$ atividade militar exige dos seus membros uma dedicaşão integral. Em grande parte de nossas vidas, passamos ausentes da familia, que também é sacrificada, estando aposentados temos a grande oportunidade de dedicarmos integralmente a ela - o que é uma experiência inusitada, uma dádiva. (Leão, 64 anos)

[A Reserva] significa ter concluido uma etapa da vida. Por sermos uma categoria que não tem perda pecuniária, ao se tornar um inativo, a [Reserva] nos proporciona certa facilidade de manter- 
se financeiramente independente. [Contudo], o militar se caracteriza por ser disciplinado e disciplinador e, estando na Reserva torna-se difícil, porque o ambiente familiar é diferente do ambiente da caserna. (Leão, 59 anos)

Apesar da preocupação do Exército brasileiro com seu contingente inativo, expresso por políticas de valorização do soldo, de assistência pecuniária e de saúde, entre outras que diferenciam o mundo civil do militar, a ida para a Reserva muda as relações de poder e micropoderes entre os trabalhadores da ativa e os inativos. Os entrevistados expressam o sentimento de serem tratados de forma distinta do militar da ativa, por terem deixado de fazer parte do cotidiano das atividades do quartel.

Estando fora do quartel - embora você fica vinculado a um deles para o resto da vida e isso passa para sua esposa e filhas -, quando você mora longe, tem dificuldade para saber de novidades e mesmo dos seus direitos, embora tenha que ir anualmente assinar o seu atestado de vida. (Águia, 62 anos)

A dificuldade em ser militar aposentado é o não reconbecimento pelas autoridades militares da ativa no FUSEX (Fundação de Saúde do Exército), tendo que entrar na fila para ser atendido e não sendo relativamente forte, morre na fila. (Águia, 72 anos)

A não adaptação à vida fora do Exército, faz com que alguns militares retornem como prestadores de serviço.

[A Reserva teve] o significado de descanso, pois não tomei gosto (...) retornei a ativa como prestador de serviço dentro do Exército. (Águia, 57 anos)

\section{Preparação para ser da Reserva}

Quando perguntado aos entrevistados se haviam planejado a vida, pensando que um dia estariam na Reserva, oito relataram não terem se preparado para a inatividade e dez mencionaram terem se preocupado com esse período. Apesar do reconhecimento de que a aposentadoria do militar assegura maior estabilidade financeira do que a de outros trabalhadores, a inserção na vida civil é uma dificuldade significativa no momento da Reserva.

Essa vida de aposentado, principalmente, na nossa classe [militar] é muito boa, mas se o inativo não se preocupar com isso [preparação para a vida na Reserva] ele poderá ter muitas surpresas ruins. (Águia, 58 anos)

Pensei que estivesse preparado; fir um curso para obter uma segunda profissão e continuar laborando, mas encontrei dificuldades de relacionamento com membros desta nova carreira. (Leão, 69 anos)

A necessidade de ter um curso superior é apontada, como uma maneira de reinserção social fora dos quartéis.

[É muito importante] ter curso superior reconhecido no meio civil para poder trabalhar um pouco mais e ser recompensado. (Águia, 72 anos)

Acrescida à necessidade da formação superior, observamos nas narrativas a preocupação com a moradia e com maior estabilidade financeira, para assegurar qualidade de vida na aposentadoria.

Sinto ter cometido dois grandes erros: não ter concluido o curso superior que comecei e não ter dado maior importância para o lado econômico. (Águia, 58 anos)

[É necessário] preparar-se intelectualmente, mantendo-se inserido socialmente, buscando uma estabilidade financeira e um bom preparo psicológico. (Leão, 64 anos)

[Avalio serfundamental] enquanto trabalhar, investir em uma moradia e preparo intelectual para construir a vida fora da Força Terrestre. (Leão, 56 anos)

Eu diria hoje aos iniciantes para enfatizar ou priorizar a formação acadêmica e também o fator financeiro. (Águia, 53 anos)

Destacaram ainda que o preparo para a Reserva não deveria ser apenas uma preocupação do militar, mas também uma política das Forças Armadas, em particular, do Exército.

É faz̧ercomo nas Forças Singulares [polícia e bombeiro], nos últimos 3 anos vão tirando o homem das atividades. (Águia, 49 anos)

Iniciar na Força Terrestre uma dinâmica de [trabalhar com] grupos 2 anos antes [da Reserva], a fim de começar a preparação de profissionais para a aposentadoria. (Águia, 61 anos)

O planejamento do militar da ativa para a vida fora do quartel é fundamental para evitar surpresas indesejáveis na vida futura.

Hoje, reconheço: poderia estar numa situação bem superior. Esses fatores representam, nesta fase da vida, prejuízos irreversiveis, mas não épossivel retroceder no tempo. (Águia, 56 anos)

\section{DISCUSSÃO}

O envelhecimento é um processo de vida e como tal comporta a velhice, mas não se esgota nela. Assim, a velhice não é uma cisão em relação a vida precedente, mas uma continuação da vida de cada um de nós. Entendendo que a vida não é só biológica, mas social e culturalmente construída, bem como a imagem que atribuímos (e/ou atribuem) a nosso corpo, acreditamos que o simbolismo presente na imagem corpórea nos diversos estágios da vida apresenta diferentes significados e duração ${ }^{(2)}$. Quanto mais entendermos que o envelhecimento é processual, mais ferramentas teremos para modificar e incorporar hábitos e valores para envelhecer com qualidade( ${ }^{(7)}$. 
Neste estudo, partimos da premissa de que nas sociedades capitalistas o trabalho tem um papel central na vida das pessoas, e a aposentadoria ou o desemprego são marcadores da percepção do envelhecimento e, não raras vezes, da velhice. A escuta atenta aos militares que entrevistamos, mostra que essa realidade não é diferente na vida militar, contudo, depreendemos diferenças significativas no universo da atividade militar em relação ao trabalho civil. Se, por um lado, o desemprego estrutural, a metamorfose do trabalho contemporâneo e a fragilização das conquistas trabalhistas são problemas para os civis ${ }^{(1-2)}$, para os militares as perdas físicas, a adaptação da vida fora dos quartéis e a reinvenção do convívio contínuo com os familiares são questões fundamentais a serem trabalhadas neste contexto de passagem da Ativa para a Reserva.

Defendemos o pressuposto de que o envelhecimento é silencioso, raramente o percebemos, contudo, identificamo-lo ao comparar nossa imagem corporal, as habilidades e/ou mudanças físicas atuais com as passadas $^{(8)}$. Desta forma, por mais que o envelhecimento seja um processo pluridimensional, é composto não só por perdas, mas, por ganhos individuais e $\operatorname{coletivos}^{(7)}$, esta comparação desnuda o mito da imortalidade.

Nas narrativas, percebemos que, para o militar a consciência das perdas funcionais, é um indicativo importante do envelhecimento, uma vez que lhe é exigido higidez e habilidade física durante toda sua vida ativa.

Por mais que o ato de envelhecer seja individual, o ser humano não é sozinho, vive com outras pessoas, em coletividade. Desta forma, recebe influências, ao mesmo tempo, em que influencia a sociedade de uma maneira geral e sua família em particular ${ }^{(7)}$.

Neste contexto, a passagem para a Reserva, não é um ato que impregna de sentido apenas o militar, mas também seus familiares. Novas relações sociais começam a ser desenhadas, contudo carregadas dos simbolismos das experiências compartilhadas no passado. O processo de adaptação na e da família será mais ou menos conturbado, dependendo das histórias pregressas dessa convivência.

Vale destacar o trabalho que vem sendo desenvolvido pelo Exército brasileiro com seus integrantes na Reserva, expresso por meio de políticas focalizadas na manutenção desse contingente, contudo, há necessidade de instituir ações para preparar os militares da ativa para a passagem à inatividade.

No que tange ao respeito aos militares inativos, merece destaque a página virtual "Conversando com a Reserva”, composta por itens que tratam desde a preocupação em localizar antigos companheiros, e manter notícias atualizadas, convite para eventos, apresentação de normas e leis, enfim, manter aberto um canal de comunicação permanente entre os militares $^{(9)}$.

\section{CONSIDERAÇÕES FINAIS}

À guisa de conclusão temos que o envelhecimento e, em particular, a velhice desencadeiam a necessidade da realização de adaptações no modo de viver a vida, tanto por parte do ser que envelhece como daqueles que com ele convivem.

Indubitavelmente, o processo de envelhecimento traz em si as mudanças de papéis sociais, alterando sobremaneira as posições que as pessoas ocupam na sociedade e, em consequência as relações que estabelecem entre si.

Com o militar, esse processo não é diferente, entretanto potencializa-se no que tange às mudanças de papéis. Se o contrato social estabelecido entre a sociedade e as Forças Armadas - no nosso caso, em particular, com o Exército -define que ao militar cabe defender os poderes constituídos, a população e o território nacional; a Reserva desencadeia mudanças substanciais nesse contrato. O militar perde esse papel, suas relações de poder e micropoderes passam a ser outras, ele entra no anonimato, e tal como outros trabalhadores aposentados, passa a ser um "ex". Muitos militares ao irem para a reserva queixam-se dos tratamentos diferenciados que lhes é dado, pelo fato de não estarem mais fazendo parte do grupo dos ativos.

Atrelada a essa questão, temos a dificuldade expressa por nossos entrevistados para lidar com as mudanças funcionais inerentes ao processo de envelhecimento, assim como a readaptação no âmbito familiar.

Como vimos dos militares, exigem rigorosos preceitos e regras que os tornam seres disciplinados e disciplinadores de corpos; fato que, se por um lado, os torna confiáveis no desempenho do contrato social firmado com a sociedade; por outro, dificulta sua passagem para a Reserva de primeira linha das Forças Armadas.

Esperamos que este estudo possibilite a ampliação de reflexões a respeito do envelhecimento no mundo militar, no sentido de implementar ações para preparação para a vida na Reserva - trabalhando não apenas com os militares, mas também com suas famílias. Quem sabe, desta forma, tenhamos contribuído para minimizar o quadro inicial que desencadeou nosso interesse ao realizar este estudo.

\section{REFERÊNCIAS}

1. Brêtas ACP, Oliveira EM. Envelhecimento, saúde e trabalho: um estudo com aposentados e aposentadas. Acta Paul Enferm. 2000;13(1):66-79.
2. Brêtas ACP. O significado do processo de envelhecimento no mercado de trabalho e suas implicações na saúde dos(as) trabalhadores(as). Texto \& Contexto Enferm. 
2001;10(2):34-51.

3. Brasil. Constituição (1988). Constituição da República Federativa do Brasil. Brasília: Senado Federal; 1988.

4. Exército Brasileiro. Missão do Exército [Internet]. Brasília (DF); 2010. [citado 2010 Abril 22]. Disponível em: http:/ /www.exercito.gov.br/060Ms/gabcmtex/por657.htm; http://www.exercito.gov.br/web/guest/missao-e-visaode-futuro; jessionid $=033 \mathrm{CEA} 7 \mathrm{C} 9 \mathrm{C} 28 \mathrm{FABFA} 55$ CF5C16F215F4B.lr2

5. Exército Brasileiro. A profissão militar [Internet]. Brasília (DF); 2006. [citado 2010 Abril 22]. Disponível em: http:/ /www.exercito.gov.br/web/guest/a-profissao-militar
6. Gil AC. Métodos e técnicas de pesquisa social. 5a. ed. São Paulo: Atlas; 2007.

7. Souza RF, Skubs T, Brêtas ACP. Envelhecimento e família: uma nova perspectiva para o cuidado de enfermagem. Rev Bras Enferm. 2007;60(3):263-7.

8. Souza RF, Matias HA, Brêtas ACP. Reflexões sobre envelhecimento e trabalho. Ciênc Saúde Coletiva. 2010;15(6):2835-43.

9. Exército Brasileiro. Conversando com a reserva. [nternet]. Brasília (DF); 2010. [citado 2010 Abril 29]. Disponível em http://www.exercito.gov.br/web/conversando-com-areserva 